\title{
Atypical form of Takotsubo cardiomyopathy
}

\author{
Fadi Jouhra, Rafal Dworakowski, Philip MacCarthy
}

Department of Cardiology, King's College Hospital, London, UK

\section{Correspondence to}

Dr Fadi Jouhra, fadi.jouhra@nhs.net
To cite: Jouhra F, Dworakowski $R$,

MacCarthy P. BMJ Case Rep Published online: [please include Day Month Year] doi:10.1136/bcr-2012008376

\section{DESCRIPTION}

A 60-year-old lady was referred to our cardiology team with troponin-positive chest pain following elective pelvic floor repair for vaginal prolapse. There were no significant ECG changes. Cardiovascular risk factors consisted of extensive history of smoking, positive family history and hyperlipidaemia. She suffered from depression and fibromyalgia. The patient exhibited normal preoperative transthoracic echocardiogram. However, transthoracic echocardiogram after the episode of chest pain showed septal, anteroseptal, anterior, inferior and posterior hypokinesis with preserved apical function and no apical ballooning. A coronary angiogram revealed unobstructed arteries. Subsequently, the patient underwent cardiac MRI which confirmed these findings and showed moderately impaired function with hypokinesia of all mid-left ventricular segments (figure 1A,B and videos 1 and 2). The apical and basal segments had relatively preserved systolic function. There was no evidence of scar on late enhancement images (figure 1C and video 3). Subsequently, the patient underwent a repeated cardiac MRI after 3 months which showed resolution of these abnormalities (figure 2A,B and videos 4 and 5).

Takotsubo cardiomyopathy is a recognised form of transient left ventricular dysfunction that is presumably caused by emotional, physical or medical stress. ${ }^{1}$ It can clinically resemble an acute coronary syndrome. ${ }^{2}$ Patients typically present with chest pain or dyspnoea, electrocardiographic changes

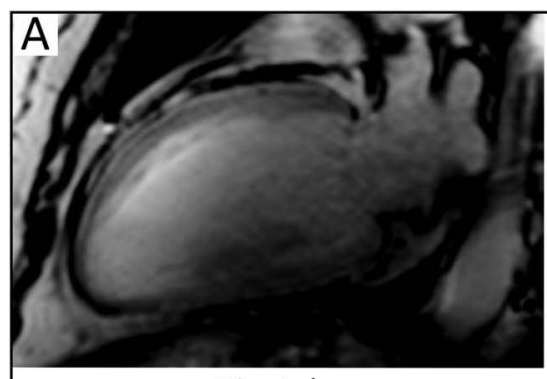

Diastole

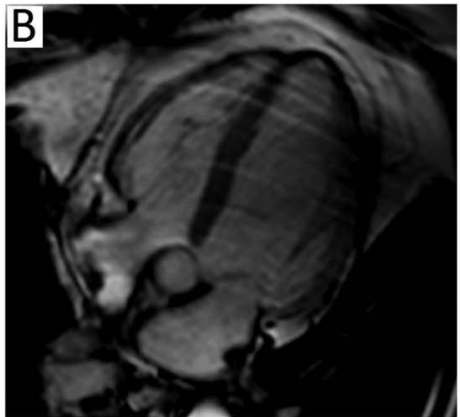

Diastole

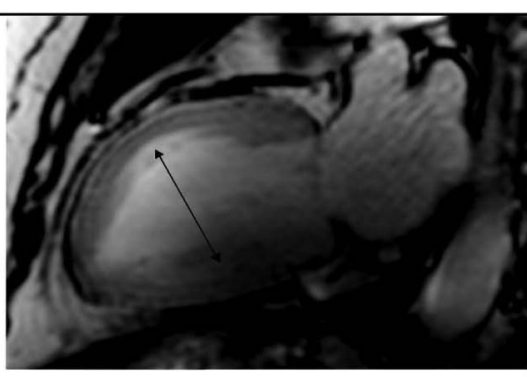

Systole

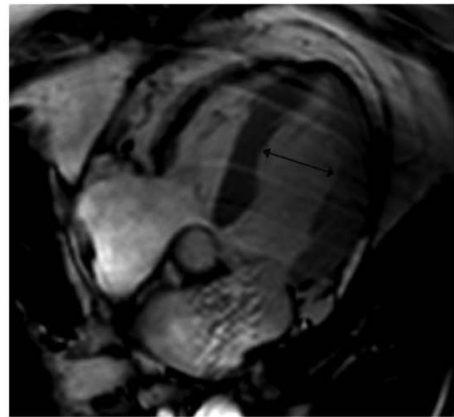

Systole

Initial cMRI - 2 and 4 chamber views

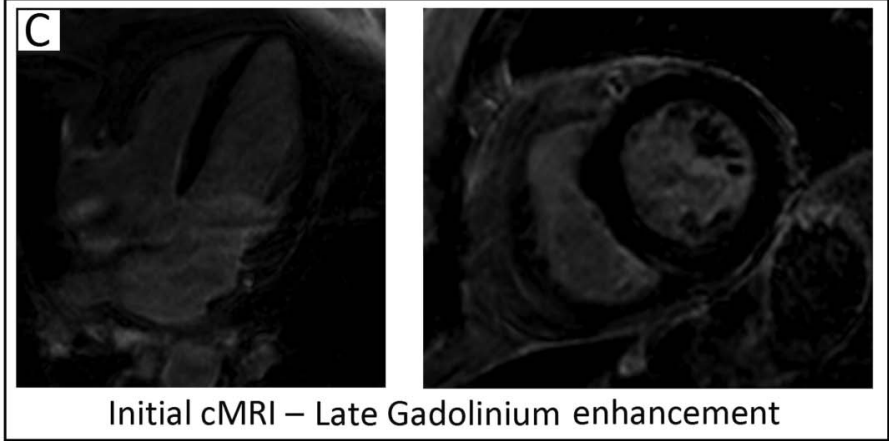

Figure 1 Initial cardiac MRI. (A and B) The 2 and 4 chamber views, images showing akinesia of the mid-ventricular segments (arrows) with preserved motion in the apical and basal regions. (C) The late gadolinium images showing no enhancement; this excludes myocardial scarring or fibrosis. 


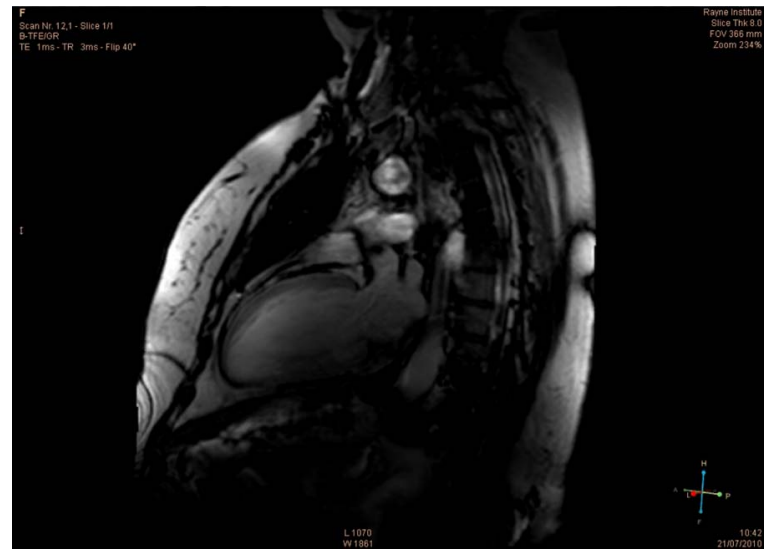

Video 1 Initial cMRI - 2 chamber view.

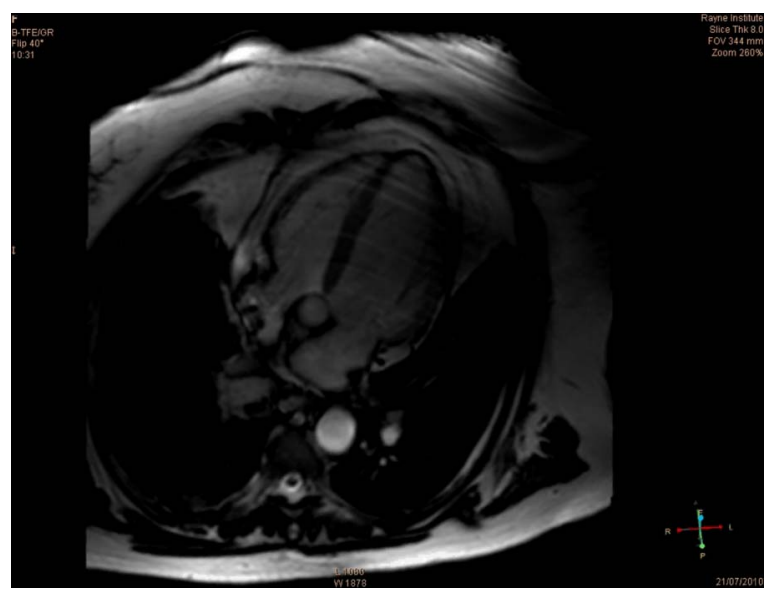

Video 2 Initial cMRI - 4 chamber view.

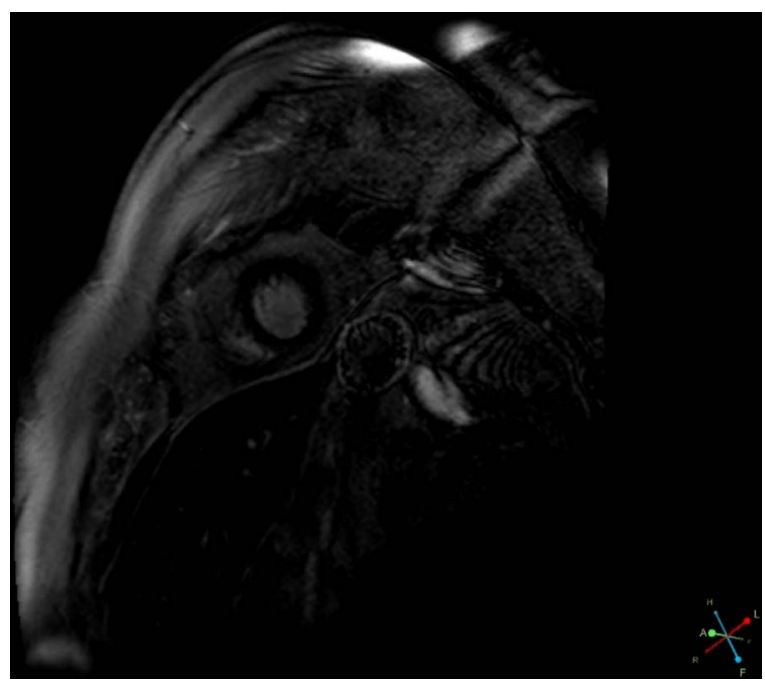

Video 3 Initial cMRI - Late Gadolinium enhancement.

consistent with acute coronary syndrome but in absence of coronary artery disease. A Takotsubo cardiomyopathy was initially described as apical ballooning with apical wall motion abnormalities. This pattern is seen in majority of patients, but there is the group of patients that present with atypical appearance with

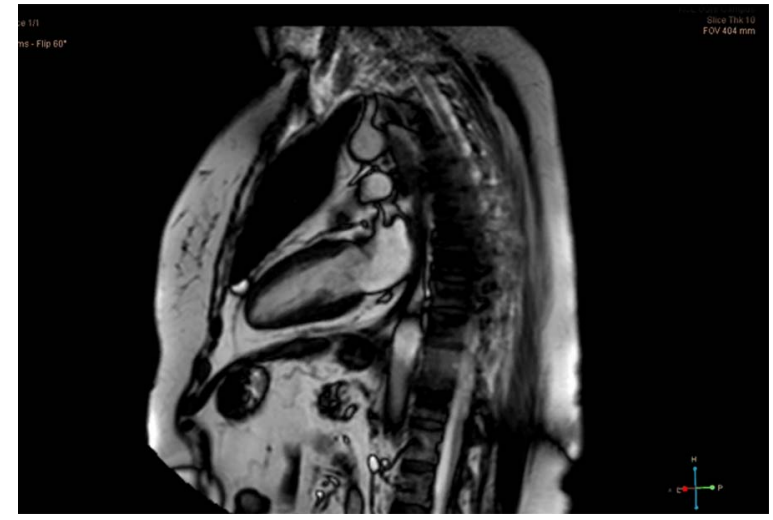

Video 4 Recovery - 2 chamber view.

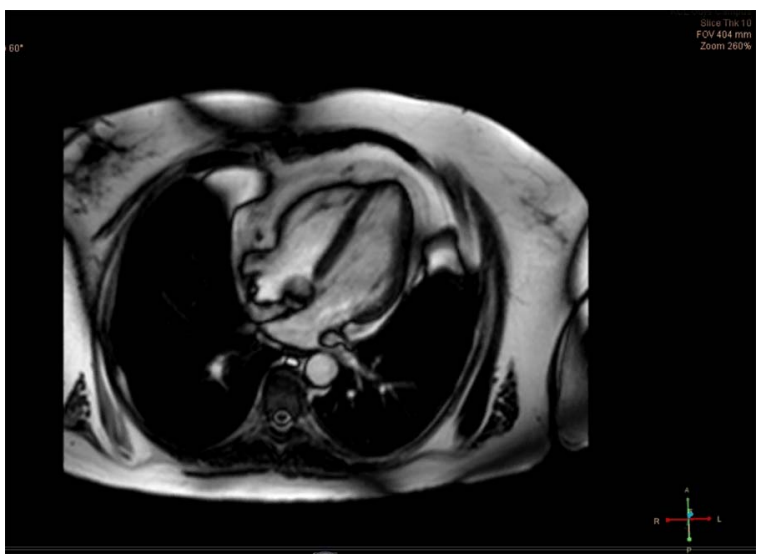

Video 5 Recovery - 4 chamber view.

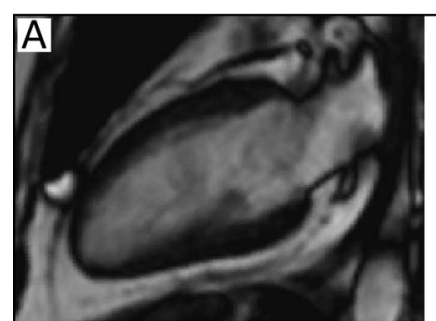

Diastole

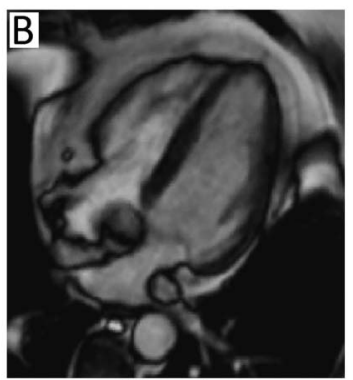

Diastole

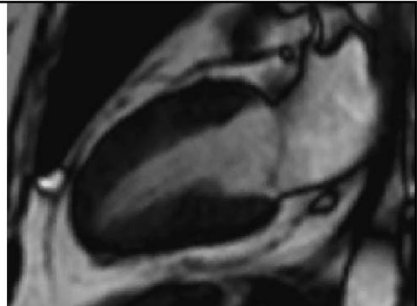

Systole

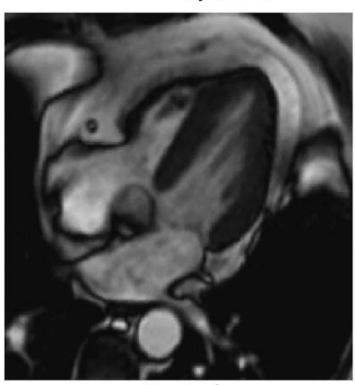

Systole
Recovery -2 and 4 chamber views

Figure 2 Cardiac MRI after 3 months (recovery). (A and B) The 2 and 4 chamber views. It is showing resolution of the regional wall motion abnormalities with good systolic function. 
mid-ventricular wall motion abnormality. ${ }^{3}$ The wall motion abnormalities in atypical forms of Takotsubo are more subtle and might be more difficult to see using standard techniques such as left ventriculogram or echocardiogram. Cardiac MRI gives a way to distinguish diagnosis of atypical Takotsubo from other aetiologies in this context. ${ }^{4}$

\section{Learning points}

- Takotsubo cardiomyopathy is identified with apical ballooning of the left ventricle. However, it can present with atypical wall motion abnormalities.

- Cardiac MRI is a very useful tool for establishing diagnosis and differentiate it from other types of cardiomyopathies.

- Takotsubo cardiomyopathy has a very good prognosis and a full recovery is expected.
Competing interests None.

Patient consent Obtained.

Provenance and peer review Not commissioned; externally peer reviewed.

\section{REFERENCES}

1 Nef HM, Möllmann H, Akashi YJ, et al. Mechanisms of stress (Takotsubo) cardiomyopathy. Nat Rev Cardiol 2010;7:187-93.

2 Seth PS, Aurigemma GP, Krasnow JM, et al. A syndrome of transient left ventricular apical wall motion abnormality in the absence of coronary disease: a perspective from the United States. Cardiology 2004;102:119-21.

3 Kurowski V, Kaiser A, Von Hof K, et al. Apical and midventricular transient left ventricular dysfunction syndrome (tako-tsubo cardiomyopathy): frequency, mechanisms, and prognosis. Chest 2007;132:809-16.

4 Haghi D, Fluechter S, Suselbeck $T$, et al. Cardiovascular magnetic resonance findings in typical versus atypical forms of the acute apical ballooning syndrome (Takotsubo cardiomyopathy). Int J Cardiol 2007;120:205-11.

Copyright 2013 BMJ Publishing Group. All rights reserved. For permission to reuse any of this content visit http://group.bmj.com/group/rights-licensing/permissions.

BMJ Case Report Fellows may re-use this article for personal use and teaching without any further permission.

Become a Fellow of BMJ Case Reports today and you can:

- Submit as many cases as you like

- Enjoy fast sympathetic peer review and rapid publication of accepted articles

- Access all the published articles

- Re-use any of the published material for personal use and teaching without further permission

For information on Institutional Fellowships contact consortiasales@bmjgroup.com

Visit casereports.bmj.com for more articles like this and to become a Fellow 